\title{
MUNDIALIZAÇÃO DO CAPITAL E AS DESIGUALDADES SOCIAIS \\ NO SÉCULO XXI: REFLEXÕES A PARTIR DE "A TEMPESTADE", DE \\ WILLIAM SHAKESPEARE
}

\section{WORLDWIDE CAPITAL AND SOCIAL INEQUALITIES IN THE 21ST \\ CENTURY: REFLECTION BASED UPON "THE TEMPEST", BY \\ WILLIAM SHAKESPEARE}

\section{Zulmar Fachin ${ }^{1}$ \\ Deise Marcelino da Silva ${ }^{2}$}

RESUMO: O artigo estuda a evolução do capitalismo e o aumento das desigualdades. Tem por objetivo refletir sobre as desigualdades socioeconômicas que marcam o século XXI, diante do fenômeno da mundialização do capital, compreendendo as diversas fases do capitalismo: manufatureiro, industrial e financeiro. Toma como ponto de partida o livro "A Tempestade", de William Shakespeare, publicado durante o período do colonialismo inglês, praticado nos séculos XVI e XVII. A metodologia da pesquisa é de natureza exploratória e teve por base textos doutrinários encontrados em livros, artigos científicos e bancos de dados públicos nacionais e internacionais. Os resultados obtidos apontam para o fato de que o capitalismo, ao tempo em que enseja produção e acúmulo de riquezas, também amplia e aprofunda as desigualdades socioeconômicas, acarretando violação a diversos direitos da personalidade.

Palavras-Chave: Shakespeare. Capital. Desigualdades.

ABSTRACT: The paper studies the capitalism evolution and the inequalities increase. It aims to reflect on the socioeconomic inequalities that mark the 21 st century, in the

\footnotetext{
${ }^{1}$ Doutor em Direito Constitucional (UFPR). Mestre em Direito (UEL). Mestre em Ciência Política (UEL). Professor no Programa de Doutorado e Mestrado da Unicesumar e na UEL. Coordenador do Programa de Mestrado Profissional em "Direito, Sociedade e Tecnologias" da Escola de Direito das Faculdades Londrina. Membro eleito da Academia Paranaense de Letras Jurídicas. Presidente do IDCC - Instituto de Direito Constitucional e Cidadania. Advogado. Pesquisador do ICETI. E-mail: zulmarfachin@uol.com.br. ORCID: http://orcid.org/0000.0001.5514.5547.

${ }^{2}$ Doutora em Direito Ambiental Internacional (Unisantos). Mestre em Ciência Jurídica (Unicesumar). Especialista em Direito Ambiental e Sustentabilidade (IDCC/UENP), em Docência no Ensino Superior (Unicesumar) e em Direito do Trabalho e Direito Previdenciário (IDCC/UENP). Professora. Advogada. E-mail: deise.marcelino@hotmail.com. ORCID: http://orcid.org/0000-0002-7938-0813
} 
face of the phenomenon of the globalization of capital, comprising the different phases of capitalism: manufacturing, industrial and financial. It takes as its starting point the book "The Tempest", by William Shakespere, published during the period of English colonialism, practiced in the 16 th and 17 th centuries. The research methodology is exploratory in nature and was based on doctrinal texts found in books, scientific articles and national and international public databases.

The results obtained point to the fact that capitalism, at the same time that it promotes production and accumulation of wealth, also widens and deepens socioeconomic inequalities, causing violation of several personality rights.

Keywords: Shakespeare. Capital. Inequalities.

Sumário: 1. Introdução. 2. William Shakespeare: A grandeza intelectual de um homem e a temática do colonialismo. 3. Capitalismo: desenvolvimento, riquezas materiais e o caminho da exclusão social. 4. Desigualdades sociais e concentração de renda no século XXI. 5. Conclusão. 6. Referências.

\section{INTRODUÇÃO}

A pesquisa é uma reflexão sobre o desenvolvimento do sistema capitalista de produção e as desigualdades sociais. Ao mesmo tempo em que enseja a produção quase ilimitada de bens e serviços, gerando riquezas materiais, o capitalismo não tem conseguido reduzir as desigualdades, contribuindo, inclusive, para sua ampliação.

Reconhece-se que os espaços geográficos e temporal da pesquisa são demasiado longos, o que poderia resultar em prejuízo do comprometimento científico dos seus resultados. Ciente de tal risco, todavia, procurou-se resgatar algumas reflexões desenvolvidas por William Shakespeare, no livro "A Tempestade", no qual se manifesta, pelo menos em parte, o pensamento colonialista dos séculos XVI e XVII. Tal interpretação exsurge dos conflitos existentes entre dois personagens do autor: Próspero, o colonizador, e Caliban, o colonizado. Em seguida, após analisar as fases evolutivas do capitalismo, a pesquisa aborda as desigualdades sociais e econômicas que, criadas, desenvolvidas e mantidas no decorrer do tempo, projetam-se sobre o século XXI, em desfavor de milhões de pessoas ao redor do mundo e, inclusive, no Brasil. De modo 
mais específico, a pesquisa analisa como a produção de riquezas não tem conseguido diminuir as desigualdades econômicas e sociais. Ao contrário, tem-nas aumentado. Essas desigualdades violam diversos direitos da personalidade, tais como o acesso à saúde e à educação.

O problema da pesquisa pode ser assim formulado: o longo processo de desenvolvimento econômico, gerador de riquezas materiais, tem sido também causa de desigualdades sociais e econômicas?

A hipótese da pesquisa está em saber se o colonialismo, primeiro, e o capitalismo, depois, foram as causas das desigualdades sociais e econômicas que se projetam sobre o século XXI, atingindo negativamente a um número cada vez maior de pessoas, ou se essas desigualdades surgiram naturalmente e estão em níveis suportáveis pelas pessoas. Em outras palavras, busca-se entender se tais desigualdades são uma decorrência do próprio evoluir da história ou se, ao contrário, são produzidas pelo desenvolvimento das condições materiais que envolvem as pessoas. Para validar a conclusão a ser obtida pela pesquisa, serão utilizados dados estatísticos fornecidos por pesquisadores autônomos ou por órgãos estatais e internacionais.

A pesquisa reconhece que o embrião do desenvolvimento do capitalismo pode ser encontrado nas grandes navegações empreendidas por portugueses (os pioneiros), espanhóis, ingleses, franceses e holandeses. Neste sentido, os dados históricos mostram que, desde o século XV, os europeus lançaram-se por mares e oceanos desconhecidos, muitas vezes em embarcações pequenas e frágeis, em busca de conquistas e riquezas materiais. Por meio dessas viagens, eles conheceram e dominaram imensos territórios e centenas de povos distribuídos em vários continentes, tais como a África, a Ásia e a América (BOULOS JÚNIOR, 1995, p. 9).

A pesquisa justifica-se pela necessidade de entender a influência do sistema de produção capitalista sobre as condições socioeconômicas das pessoas. Torna-se importante compreender o desenvolvimento do capitalismo, bem como identificar as desigualdades sociais e econômicas que precisam ser combatidas, visto que todas as 
pessoas tem o direito de acesso aos bens fundamentais da vida. O capitalismo desenhou no tempo uma longa trajetória de acumulação de riquezas, valendo-se, cada vez mais, de modernas tecnologias que jamais cessaram de avançar. A produção de riquezas, contudo, sujeitou-se, ao longo do tempo, e ainda hoje se submete, a um processo forçado de acumulação, deixando que as desigualdades sociais e econômicas continuem atingindo um número cada vez mais amplo de pessoas, acarretando progressivas violações a direitos da personalidade.

Pode-se afirmar, ainda, que a pesquisa se justifica pela dimensão axiológica do tema pesquisado. Ela contempla conteúdos econômico e social, os quais impactam na qualidade das condições de vida das pessoas, visto que as condições econômicas devem nortear o grau dos benefícios sociais, assegurando-se às pessoas o acesso aos bens necessários para sua própria subsistência.

Para compreender o processo de acumulação de riquezas e a disseminação das desigualdades econômicas e sociais, tomou-se como ponto de partida o livro "A Tempestade", de William Shakespeare. Nessa obra, o autor retrata, em diversas passagens, o fenômeno da colonização, tão comum aos ingleses e europeus dos séculos XVI e XVII. Parece ser possível afirmar que o sistema de produção capitalista, desenvolvido nos séculos seguintes e bastante aperfeiçoado nos dias de hoje, não renegou os princípios que inspiravam a colonização, como a ideia de obter lucros em lugares distantes, explorando o trabalho executado pelos nativos.

\section{WILLIAM SHAKESPEARE: A GRANDEZA INTELECTUAL DE UM HOMEM E A TEMÁTICA DO COLONIALISMO}

William Shakespeare (1564-1616) nasceu em Stratford-upon-Avon, na Inglaterra. Era filho de John Shakespeare, rico comerciante e funcionário público ${ }^{3}$, e

\footnotetext{
${ }^{3}$ Exerceu por muito tempo vários cargos na administração da cidade, o que poderia ser definido, nos dias atuais, como um servidor público.
} 
Mary Arden, também descendente de família rica (SHAKESPEARE, 2019a, p. 5). É provável que ele tenha nascido em 23 de abril de 1565, porém a data é incerta. Residindo com seus pais nos primeiros anos de vida, foi matriculado na Free Grammar School, porém abandonou os estudos aos 15 anos de idade.

Pouco se sabe acerca de sua infância e adolescência (SHAKESPEARE, 2019b, p. 5). Aos 18 anos, casou-se com Ann Hathaway, filha de um fazendeiro das redondezas. Dessa união, nasceram três filhos: Susanna, Judith e Hamnet. Irmão gêmeo de Judith, Hamnet faleceu aos 11 anos de idade. Foi inspirado nele que Shakespeare intitulou uma de suas peças, Hamlet, a mais longa que escreveu. Nessa obra o autor imortalizou um dilema existencial: "Ser ou não ser, eis a questão!"4 (SHAKESPEARE, 2001, p. 56).

Após dificuldades financeiras enfrentadas por seu pai, até então rico comerciante, Shakespeare mudou-se para Londres, considerada, à época, o centro da vida intelectual da Inglaterra. Em Londres, trabalhou como guardador de cavalos em frente ao teatro, que, àquela época, era muito frequentado, sempre repleto de espectadores (SHAKESPEARE, 2019a, p. 7), pois já se vivia o período de ouro do "teatro elisabetano". Mais tarde, nesse mesmo teatro, ele viria a ser o grande protagonista, iniciando uma virtuosa trajetória, estudada e admirada até os dias de hoje. No auge de sua carreira, atuou no The Globe, teatro que tinha esse nome em razão da sua arquitetura em forma de globo. O próprio autor, com o passar dos tempos, adquiriu o Globe Theatre, no qual encenava peças, inclusive as que escrevia, multiplicando seu sucesso e também os rendimentos, tornando-se um homem rico para os padrões do seu tempo.

William Shakespeare foi contemporâneo de outros autores que se notabilizaram na dramaturgia, na Inglaterra pós-Renascentista. Entre os principais, podem ser mencionados Thomas Kyd, autor de The Spanish Tragedy, escrita entre 1582 e 1592, e Christopher Marlowe, que escreveu Tamburlaine, the Jew of Malta (Tamburlaine, o Judeu de Malta), em 1587. Lembra Sílvio Luiz Paradiso que, para alguns críticos, estas

\footnotetext{
4 "Ser ou não ser, eis a questão!/Que é mais nobre para a alma:/sofrer os dardos e setas de um destino cruel,/ou pegar em armas contra um mar de calamidades/para pôr-lhes fim, resistindo?/Morrer...dormir, nada mais!" (SHAKESPEARE, 2001, p. 56).
} 
duas obras deram início à fase de ouro do "teatro elisabetano" (PARADISO, 2019, p. 69), período no qual a obra shakespereana se desenvolveu.

Shakespeare foi um verdadeiro cânone da Literatura inglesa e mundial. Tem sido reconhecido como o dramaturgo mais influente do mundo ou um dos maiores gênios da literatura mundial ou ainda o maior escritor que o mundo de língua inglesa já conheceu e jamais conhecerá (SUTHERLAND, 2019, p. 52). Ao longo de sua intensa vida intelectual, dedicou-se à comédia, à tragédia e à tragicomédia, tendo legado uma vasta produção intelectual que abrange também dramas históricos, poemas narrativos e sonetos. O corpus literário do autor é composto por 37 peças e 154 sonetos, estes, em sua maioria, escritos "provavelmente durante um verão no qual os teatros ao ar livre estiveram fechados, como ficavam com frequência durante surtos de peste" (SUTHERLAND, 2019, p. 56). Foi traduzido para muitos idiomas, tendo sido adaptado ao teatro, cinema e televisão.

Com sua vasta obra, Shakespeare enriqueceu significativamente o teatro inglês e mundial. Ele teria acrescentado à Linguística cerca de 3 mil palavras e expressões ${ }^{5}$, transformando-se em verdadeiro The Bard. ${ }^{6}$

Suas principais obras podem ser relacionadas e classificadas desse modo: nas peças históricas, "Ricardo II", "Ricardo III", "Henrique IV (Partes I e II)", "Henrique V", "Henrique VI (Partes I, II e III)", "Henrique VIII", "Rei João" e "Eduardo III"; na poesia, "Vênus e Adônis", "O Rapto de Lucrécia" e "Sonetos"; na comédia, "O Mercador de Veneza", "A Comédia dos Erros", "Os Dois Cavalheiros de Verona", "Sonho de Uma Noite de Verão", "Muito Barulho Por Nada", "Cimbelino", "Noite de

\footnotetext{
${ }^{5}$ Apenas a título exemplificativo, podem ser mencionadas as seguintes: good riddance (já vai tarde); what's done is done (o que está feito, está feito); break the ice (quebrar o gelo); devil incarnate (diabo encarnado); dishearten (sem coração); new-fangled (novo e já obsoleto); with bated breath (com a respiração suspensa); a heart of gold (coração de ouro); not slept one wink (não dormi nem uma piscada); obscene (obsceno); bedazzled (estupefato); lonely (solitário); come what, come may (aconteça o que acontecer).

6 "O Bardo" expressa a ideia de grande trovador, de cantores populares e contadores de histórias, de pessoas dotadas de vocação e que, com ineditismo, contavam e transmitiam histórias do povo.
} 
Reis", "Como Quiserdes" e "A Megera Domada"; na tragédia, "Romeu e Julieta", "Júlio César", "Antônio e Cleópatra", "Hamlet", "Otelo", "Rei Lear", "Macbeth" e "A Tempestade".

Em 1588, a Inglaterra derrotou a poderosa armada espanhola, estendendo seu controle sobre o Atlântico Norte, dando início ao Império Britânico. Mais tarde, por meio da Companhia das Índias Orientais, passou a exercer influência também sobre o Oriente. Neste sentido, o British Empire foi avançando sobre vastas terras e diferentes povos, abrangendo colônias, protetorados, domínios e mandatos até se tornar o maior império do mundo, tão vasto que, por se estender sobre vários continentes, foi conhecido como "o império onde o sol não se põe".

No reinado de Elizabeth (Isabel I de Inglaterra), de 1558 a 1603, a Inglaterra viveu uma era de grande desenvolvimento e expansão do império. O teatro floresceu e se notabilizou, sendo conhecido como o "teatro elisabetano". Nesse contexto, destacouse William Shakespeare.

"A Tempestade" foi sua última peça (GALVÃO, 2016; PARADISO, 2019, p. 136), embora o mesmo se afirme em relação a Henrique VIII (SUTHERLAND, 2019, p. 53). Ela foi escrita quando o autor estava de volta à sua cidade natal, aonde viveu os derradeiros anos da sua vida. Este livro foi escolhido como ponto de partida da presente reflexão, justificando-se a escolha pelo fato de que, nele, William Shakespeare abordou o colonialismo promovido pela Inglaterra naquele período histórico ${ }^{7}$. A peça teatral é um romance, classificado como tragédia.

Para a finalidade desta pesquisa, destacam-se dois personagens como tema do livro: Próspero, simbolizando o colonizador, e Caliban, traduzindo a condição do colonizado. Acredita-se que a peça foi escrita entre 1610 e 1611, tendo sido publicada no First Folio, em 1623, a primeira coleção de Comédias, Histórias, e Tragédias publicada pelo autor.

\footnotetext{
${ }^{7}$ A Inglaterra foi a mais forte potência econômica entre 1583 e 1783. William Shakespeare viveu durante parte desse período (1564-1616). No início do século XVI, sob o reinado de Henrique VIII, os ingleses passaram a desenvolver o projeto de dominar o mundo.
} 
É importante observar que a introdução desse tema (colonização) em obra de William Shekespeare justifica-se porque o autor foi contemporâneo à época em que foram desenvolvidas navegações, expansões e conquistas de territórios localizados em outras partes do mundo. Tais desafios eram comuns a espanhóis, portugueses e ingleses, tendo, inclusive, se protraído no tempo, conforme retratam Daniel Defoe, com seu Robinson Crusoé (1719), e Lemuel Gulliver, com As Viagens de Gulliver (1726). Poderse-ia afirmar que, naquela quadra da história, uma aventura de viagem retratando as relações entre colonizador e colonizado era tema tão comum como é hoje uma canção que expressa determinada relação amorosa ou social pela internet.

O livro condensa uma história com muitas nuances: traição, amor, vingança e colonialismo.

A traição, de natureza política, ocorreu quando Próspero era o duque de Milão. Antonio, seu irmão, mancomunado com Alonso, rei de Nápoles, traiu a Próspero, usurpando para si aquele ducado. Tudo aconteceu porque Próspero confiava em Antonio, e foi essa confiança que fez nascer no irmão o desejo da traição, visto que ele "julgou tornar-se de Milão o único dono" (...), "em troca de vassalagem e do estipulado tributo" (SHAKESPEARE, 2000, p. 17-18).

O amor manifesta-se no casamento de Miranda, filha de Próspero, com Ferdinando, filho de Alonso, rei de Nápoles. Os dois jovens foram levados à ilha pelo ardiloso Próspero. Lá, o amor entre ambos aconteceu de repente. Quando vê Ferdinando, Miranda se emociona: "Oh céus! Que olhar o dele! (...) Jamais coisa natural vi tão nobre" (SHAKESPEARE, 2000, p. 32). O sentimento amoroso também se manifestou em Ferdinando, o qual, igualmente apaixonado, exclama: "Ó maravilha! Sois humana ou divina? Que sois?" (SHAKESPEARE, 2000, p. 32). E, mais tarde, quando Procópio estrategista, simulando não querer aquela união, embora a tivesse tramado -, levanta obstáculo entre os dois, Miranda implora: "Pai, compaixão!" (SHAKESPEARE, 2000, p. 35). 
Contudo, tempos depois, quando a armação de Próspero se fechou, os jovens convergiram para a união entre si. Ferdinando afirma: "Sim, aceito-vos o coração com o mesmo entusiasmo que a escravidão aceita a liberdade. Eis minha mão". Nesse instante, Miranda adere: "E a minha está aqui, com ela vos dou meu coração". A cena gera em Próspero manifestação de vitória: "coisa nenhuma me deixa tão alegre" (SHAKESPEARE, 2000, p. 68-69).

A vingança foi urdida por Próspero, tendo Antonio como alvo, mas realizado por meio do casamento entre Miranda e Ferdinando. Para tanto, Próspero, usando seus poderes sobrenaturais, desencadeou uma tempestade, atraindo também Antonio e Alonso para a ilha deserta.

O colonialismo também aparece como uma dimensão na obra de Shakespeare, especialmente nos diálogos conflituosos entre Próspero e Caliban. Na peça, Caliban, o colonizado, era o nativo taxado de inculto, disforme, velhaco, mentiroso, servil, abominável e subversivo. Já Próspero, o colonizador, fez de Caliban seu escravo, ao passo que este se negava a acatar as ordens de Próspero, o que estabeleceu o primeiro conflito de interesses entre o colonizador e o colonizado.

Próspero e Caliban relacionam-se na ilha com hostilidades recíprocas. Próspero, em seu desprezo pelo colonizado, afirma: "Vem para fora, escravo venenoso, pelo próprio diabo gerado em tua mãe maldita", ao passo que Caliban, diante de Próspero e Ariel, retruca: "que em vós dois caia o orvalho tão nocivo como o que minha mãe tinha por hábito colher nos charcos pútridos com uma asa negra de corvo. Em vós sofre o suloeste e vos deixe cobertos de feridas" (SHAKESPEARE, 2000, p. 27)

É possível deduzir que Caliban acreditava em divindades (na força dos espíritos), em que o poder do vento suloeste poderia cobrir de feridas mortais o colonizador que viera para escravizá-lo. Percebe-se, também, nesse diálogo as relações hostis entre o colonizador e o colonizado, aquele tentando fazer valer seu poder e este se negando a subordinar-se. 
Miranda, filha de Próspero, tem por Caliban o mesmo desprezo que o pai cultiva por ele. Ela concebe o escravo como um velhaco, cuja visita à sua casa suscitava repugnância. O colonizador, pragmático e movido por interesse próprio, adverte à filha sobre a utilidade do escravo: "Contudo, não podemos dispensá-lo. Acende-nos o fogo, traz-nos lenha e nos presta serviços de muita utilidade" (SHAKESPEARE, 2000, p. 27).

As relações que se desenvolveram na ilha foram cenas típicas de colonialismo, em que o colonizador explora os nativos. Estes tem utilidade e convivem com o colonizador, mas apenas e enquanto servirem aos seus interesses.

Registre-se que, nos tempos de William Shakespeare, o colonialismo era inspirado por ambições políticas e econômicas. Reis e mercadores comungavam interesses e desafios. Obter lucros em outras partes do mundo foi ideário que moveu o colonialismo, mas que, mais tarde, também embalou sonhos idealizados e realizados pelo sistema capitalista de produção.

\section{CAPITALISMO: DESENVOLVIMENTO, RIQUEZAS MATERIAIS E O CAMINHO DA EXCLUSÃO SOCIAL}

O capitalismo é uma categoria histórica. Pode-se afirmar que, voltado à acumulação de riquezas, ele surgiu a partir da ampliação do desejo de acúmulo de riquezas. Um olhar sobre a História permite afirmar que desde o surgimento até os dias atuais existiram várias espécies de capitalismo: o manufatureiro, o industrial e o financeiro.

O salto das grandes navegações era expressão da ambição que dominava dois setores da Europa: os mercadores, que forneciam o capital necessário, e os reis, que garantiam proteção e ajuda para aqueles desenvolverem seus negócios. Já se notava, àquela época, a presença de algum desenvolvimento técnico e científico, de modo que a navegação em alto mar era feita com o auxílio da bússola, do astrolábio, da pólvora, da cartografia e da caravela. 
Os aventureiros de alto mar carregavam em seus alforjes a ambição desmedida por dois valores: poder e riqueza. Fizeram da América, Ásia e África um vasto e reluzente terreno que ensejava a acumulação. Daí por diante, o capitalismo, em qualquer de suas formas, tem sido sinônimo de sucessos econômico e financeiro. Com as conquistas das grandes navegações, a descoberta e exploração das riquezas passaram a ser feitas organizadamente, possibilitando a acumulação cada vez mais intensa de riquezas em benefício dos europeus. A cobiça recaía sobre diversos produtos: ouro, prata, pimenta, açúcar, tecidos, tabaco, perfumes, pérolas etc. O mercado, que antes se movia nos limites da localidade ou da região, passou a ser praticado em escala mundial.

O capitalismo tornava-se manufatureiro e, nesse contexto, começava a exploração da força de trabalho do homem. Ao mesmo tempo em que exploravam as terras descobertas, os empresários (aventureiros) da Europa, empregando grande número de pessoas, investiam capital em atividades produtivas (manufatura) cujos produtos eram vendidos no nascente mercado mundial. $\mathrm{O}$ investimento de capitais e a contratação de mão de obra para produção em massa exigem uma certa organização na execução dos trabalhos.

O capitalismo manufatureiro foi capaz de explorar, em certa medida, a possibilidade de aumentar a produtividade mediante a produção em grande escala. Reunindo numerosos trabalhadores sob o mesmo teto, o capitalismo manufatureiro pôde criar uma divisão técnica do trabalho dentro da manufatura. Em lugar de cada trabalhador realizar todas as operações, cada operação passava a ser tarefa de um grupo específico de trabalhadores (SINGER, 1998, p. 16).

Adam Smith (1723-1790) foi um autor que ofereceu suporte teórico aos empresários que, mais tarde, conceberam a Revolução Industrial. Então jovem professor escocês, ele mostrou como se dava a divisão do trabalho na sociedade manufatureira, mas já na sua passagem para a sociedade industrial. Podem ser extraídas dos seus estudos as seguintes lições: a) a melhora na destreza do operário aumenta a quantidade de trabalho que ele pode fazer, ou seja, melhora sua produtividade; b) é mais vantajoso 
exercer atividade específica, não necessitando mudar de um lugar para outro com o objetivo de executar trabalho diverso. Ademais, se não precisa executar uma variedade de tarefas, mas pode dirigir toda a atenção da sua mente para um único objetivo, o trabalhador tende a descobrir novos e eficazes métodos para alcançar tais objetivos. Em outras palavras, quando cada indivíduo se torna mais experto em um ramo particular, mais trabalho é feito em favor do todo e o conhecimento será sempre mais elevado; c) com o uso de máquinas adequadas, um homem consegue fazer o trabalho equivalente a muitas pessoas, abreviando o tempo e aumentando a produtividade. Nesse contexto, a invenção de todas as máquinas utilizadas para a execução dos trabalhos, antes executados pela mão do homem, resultou em mudanças profundas na forma de gerar riquezas (SMITH, 2017, p. 30-34).

$\mathrm{Na}$ segunda metade do século XVIII, na Inglaterra, ocorreu a Revolução Industrial, propiciando o nascimento do capitalismo industrial. A revolução desenvolveu-se entre o final do século XVIII e início do século XIX, sendo anterior e, ao mesmo tempo, contemporânea à Revolução Francesa (1789). Este período foi marcado por várias inovações, entre as quais a spinning-jenny (roda de fiar capaz de produzir, pelo menos, oito fios ao mesmo tempo), a water-frame (máquina de fiar hidráulica e mais rápida que a anterior), o tear mecânico e o aperfeiçoamento da máquina a vapor.

Tudo isso culminou, no início do século XIX, com a invenção do barco a vapor e a locomotiva. As invenções e aperfeiçoamentos da tecnologia permitiram a passagem da manufatura, desenvolvida pelos homens, para a maquinofatura, com o predomínio das máquinas.

Na manufatura, a operação é realizada pelo trabalhador com o auxílio da ferramenta. Na maquinofatura, a ferramenta é engatada numa máquina, que substitui o trabalhador na realização da tarefa. O trabalhador, em vez de produzir, passa a ser necessário apenas para regular, carregar e acionar a máquina e depois para desligá-la e pô-la novamente em condições de funcionar. Na perspectiva da produção em grande 
escala, a máquina é mais "produtiva" do que o homem porque supera facilmente os limites físicos do organismo humano. Movida por força hidráulica e pouco depois pela energia do vapor, a máquina pode dar conta de trabalhos para os quais o homem é fraco demais. Além disso, ela pode ser acelerada, atingindo velocidades de movimento inalcançáveis para o homem. Por tudo isso, a substituição do homem pela máquina apresenta vantagens inegáveis para o capital, pela redução do custo de produção que proporciona (SINGER, 1998, p. 16-17).

O trabalhador passou a ser substituído - com vantagens para o capital - pela máquina. Nasceu o capitalismo industrial como superação do capitalismo manufatureiro.

Tratam-se de fases distintas do capitalismo. O capitalismo manufatureiro necessita, para expandir-se, que o mercado nacional seja unificado e que sua dominação seja garantida pelo monopólio político. É necessário que o Estado intervenha para protegê-lo nas disputas do mercado. Já o capitalismo industrial almeja a unificação de todos os mercados, independentemente de linhas geográficas, deseja para o capital a livre competição no mercado e repele qualquer tipo de intervenção estatal para regrar a competição. Esta concepção capitalista tem no liberalismo sua versão política.

Vale ressaltar que a Revolução Industrial ensejou uma profunda transformação no modo de produção de bens materiais nos países europeus, forjando o nascimento e a consolidação do capitalismo industrial. Esta fase do capitalismo desenvolveu-se na Inglaterra e, mais tarde, nos demais países europeus, Japão e Estados Unidos da América (HOBSBAWM, 2000, p. 43-49). Com o passar do tempo, no entanto, esse modelo de capitalismo foi dando espaço para o capitalismo financeiro.

Evoluiu-se para o capitalismo financeiro, o qual adquiriu proporções imensuráveis com o fenômeno da mundialização financeira. Esta teve início no fim da década de 1960 e chegou a um ponto elevado nos governos de Margaret Thatcher, na Inglaterra, e Ronald Reagan, nos Estados Unidos da América, estando, até os dias atuais, em pleno desenvolvimento. 
Vale registrar que, segundo François Chesnais, esse processo de mundialização financeira nasceu a partir de um processo de interação, em um espaço de cerca de quinze anos, entre o movimento de fortalecimento do capital privado - tanto industrial como bancário - e o crescente impasse das políticas governamentais existentes à época (CHESNAIS, 1998, p. 16-17).

Em outro estudo, François Chesnais lembra que a mundialização resultou de dois movimentos, estreitamento interligados, porém distintos entre si. O primeiro foi o resultado da mais longa fase de acumulação ininterrupta do capital que o sistema capitalista conheceu, tomando-se como marco inicial 1914. O segundo refere-se às políticas de liberalização, privatização, desregulamentação e desmantelamento de conquistas sociais e democráticas, as quais foram aplicadas desde o início da década de 1980, sob o impulso dos governos de Margaret Thatcher e Ronald Reagan (CHESNAIS, 1998, p. 34).

Nesse contexto, assistiu-se ao triunfo da ideia liberal, sem que outro pensamento divergente pudesse ser invocada com sucesso na construção de um espaço de equilíbrio econômico-social. Analisando a mundialização do capital naquele momento histórico, Alan Minc constatou a existência e funcionamento de 'um pensamento único', visto que, de Londres a Singapura, de Nova Iorque a Tóquio, os chamados operadores do mercado - "esse estranho lumpem inteligentsia com poderes ilimitados" - reagem de modo concatenado, impondo suas ideias e suas forças. Para o autor, diante dessa força avassaladora, não restou outra alternativa a não ser "aceitar a filosofia dos mercados financeiros, tal como ela se apresenta, detestá-la no segredo da nossa alma, mas tratá-la como uma realidade, sob pena de receber violentos choques em resposta" (MINC, 1999, p. 13-15).

O projeto desses senhores do universo desenvolve-se e - pelo menos na aparência - caminha para uma completa realização. O dinheiro, que parece ser a mais universal das linguagens, é o sangue sem o qual o coração dos organismos econômicos e financeiros não bate. E os mecanismos dos quais o capital se utilizou e ainda dispõe tem 
sido suficiente para sua mobilidade em qualquer parte do mundo onde quer que ele pretenda estar. Seus tentáculos tornam-se cada vez mais eficazes, à medida em que o tempo passa, dia após dia, ano após ano, década após década e - talvez o tempo o comprove - século após século.

No modelo do capitalismo financeiro - que triunfa soberano no século XXI -, o que importa ao capital é obter o máximo de lucro no mínimo de tempo possível. Favorecido pelas modernas tecnologias que não param de evoluir, o capital financeiro locomove-se, com imensa facilidade e rapidez, de um País a outro, de uma parte do mundo à outra. Vale-se, para isso, das modernas tecnologias que não param de avançar. Se, no rastro de sua escalada, ficarem desigualdades e aumentar o número de pobres, tais problemas a ele não dizem respeito. Nessa ordem de ideias, caberá ao Estado-nação encontrar alguma forma de aplacar as necessidades humanas - ou estas permanecerão, com tendência à ampliação, proporcionando sofrimentos a um número cada vez maior de pessoas.

O desenvolvimento do capitalismo, em todas as suas fases, ao lado de ensejar a produção de riquezas, gerou desigualdades sociais e econômicas. Tais desigualdades ficaram escancaradas ao longo do século XX e, além disso, continuam se intensificando neste século XXI.

\section{DESIGUALDADES SOCIAIS E CONCENTRAÇÃO DE RENDA NO SÉCULO XXI}

O processo de colonização, iniciado no século XV e desenvolvido nos séculos seguintes, ensejou o enriquecimento de países em detrimento de outros. Os colonizadores ampliaram riquezas, ao passo que os colonizados sofreram as consequências dessa exploração.

O sistema de produção capitalista, assim como o processo de colonização, gerou (e continua a gerar) riquezas, ensejando o desenvolvimento de potencialidades 
individuais. Ao lado desse efeito, contudo, o capitalismo tem deixado em seu rastro desigualdades que se espalham ao redor do mundo. Pode-se afirmar que tais desigualdades se intensificam em duas dimensões: horizontal, com a multiplicação do número de pessoas que empobrecem, e vertical, visto que aumenta a distância das rendas auferidas entre os mais ricos e os mais pobres.

As desigualdades medram por toda parte do globo terrestre. Se é verdade que elas se manifestaram - e continuam gerando suas consequências - em países colonizados, não se pode deixar de reconhecer que se revelam também no seio de países ricos, visto que as desigualdades não escolhem espaços geográficos. Em outras palavras, as desigualdades aumentam não apenas em países pobres, mas igualmente em países econômica e socialmente mais desenvolvidos.

O aumento das desigualdades no mundo pode ser traduzido pelos números apresentados por agências estatais e internacionais, mas também por pesquisadores autônomos. Neste sentido, Zygmunt Bauman lembra que, no período do Iluminismo, durante a vida de Francis Bacon, Descartes e Hegel, o padrão de vida em qualquer lugar da Terra nunca era mais que duas vezes superior ao padrão de vida em vigor na região mais pobre. Conclui o autor que, no início do século XXI, o Catar, tido como o país mais rico do mundo com PIB per capita anual de cerca de 100 mil dólares, se vangloria de ter uma renda per capita 428 vezes maior que à de Zimbábue, considerado o país mais pobre do mundo ${ }^{8}$ com 589 dólares de renda per capita anual (BAUMAN, 2015, p. $10)$.

De acordo com Zygmunt Bauman, estudos mostram que em quase toda parte do mundo as desigualdades crescem de modo acelerado, gerando consequências preocupantes: "os ricos, em particular os muito ricos, ficam mais ricos, enquanto os pobres, em particular os muito pobres, ficam mais pobres", tanto em termos relativos como em termos absolutos. Este fenômeno, segundo o autor, tem gerado outra

\footnotetext{
${ }^{8}$ Em relação a qual ser o país mais pobre do mundo, percebeu-se na pesquisa que há divergências, as quais devem ser atribuídas, certamente, a adoção de critérios diferentes. Encontrou-se como ocupantes desta lamentável posição diferentes países: Borundi, Congo, Serra Leoa e Zimbábue.
} 
consequência, visto que "as pessoas que são mais ricas estão ficando mais ricas apenas porque já são ricas. Pessoas que são pobres estão ficando mais pobres apenas porque já são pobres" (BAUMAN, 2015, p. 19).

Segundo dados publicados pela Organização das Nações Unidas (ONU), em 2018, cerca de 3,4 bilhões de pessoas, ou seja, quase a metade da população mundial, vivem em situação de extrema pobreza e lutam com imensas dificuldades para suprir suas necessidades básicas, tais como saúde, educação e alimentação. Vale registrar que, o relatório bienal do Banco Mundial sobre Pobreza e Prosperidade Compartilhada, intitulado "Montando o Quebra-Cabeça da Pobreza", considera que vivem na pobreza extrema, em países de renda média-baixa, as pessoas que recebem até 3,2 dólares por dia e, em países com renda média-alta, as que recebem até 5,50 dólares por dia (ONU, 2018).

O Brasil também apresenta números alarmantes, no que tange a diversos indicadores sociais e econômicos, reveladores de profundas desigualdades. Não se trata, obviamente, de uma novidade, eis que essas desigualdades já se constituem em uma marca indelével da nossa história de País soberano. O que tem se tornado mais grave, todavia, é o seu grau de intensidade.

Segundo dados do IBGE, publicados em 2019, o número de pessoas que vivem em situação de extrema pobreza no Brasil é de 13,5 milhões. Registre-se que, ao atingir este número, o total da população brasileira na extrema pobreza superou a população de diversos países do mundo, tais como Portugal, Bélgica, Bolívia e a soma de Dinamarca e Uruguai. Vale registrar, ainda, que, no ranking do Índice de Desenvolvimento Humano (IDH), publicado pela ONU, o Brasil ocupa no mundo a 79ª colocação. Na América do Sul, em $4^{\circ}$ lugar, fica atrás de Chile, Argentina e Uruguai (ONU, 2019).

Quando se trata de concentração de renda, as desigualdades se repetem. De acordo com dados do IBGE, em 2018, o rendimento mensal médio do $1 \%$ da população mais rica é cerca de 34 vezes superior à renda média mensal dos 50\% menos favorecidos. 
Nesse contexto, a renda mensal desse $1 \%$ mais rico é de $\mathrm{R} \$ 27.744,00$ mensais, ao passo que os 50\% menos favorecidos ganham, por pessoa, R\$ 820,00 mensais (IBGE, 2019).

No mesmo sentido, a Pesquisa Nacional por Amostra de Domicílios Contínua, realizada pelo IBGE, revelou que, em $2018,10 \%$ da população mais rica recebe $43,1 \%$ de toda a massa de rendimentos do País, ao passo que os $90 \%$ restantes recebem $56,9 \%$ de toda a massa de rendimentos do País. No mesmo sentido, 10\% das pessoas com menores rendimentos detém $0,8 \%$ da massa de rendimentos, enquanto os $10 \%$ com maiores rendimentos detém 43,1\% da massa de rendimentos (IBGE, 2019).

As desigualdades sociais provocadas pela concentração de renda e pela baixa remuneração resultam em violações a diversos direitos fundamentais e da personalidade. Isso ocorre de modo mais evidente em relação ao direito à saúde. Esse direito é essencial para que as pessoas possam ter acesso a outros direitos, podendo-se identificar, aqui, a complementaridade entre direitos.

É importante reconhecer, neste campo, que a Constituição brasileira de 1988 deu ampla proteção ao direito à saúde. Um dos tripés da seguridade social, ao mesmo tempo em que é dever do Estado, a saúde foi concebida como direito fundamental (art. $6^{\circ}$ ) assegurado a todas as pessoas, devendo ser garantido por meio de políticas não somente sociais, mas também econômicas e ambientais, que tenham por finalidade reduzir os riscos de doença e outros agravos à saúde das pessoas. Neste sentido, a Constituição garante o acesso universal e igualitário às ações e serviços para sua promoção, proteção e recuperação (art. 196). Para alcançar esse objetivo, foi criado o sistema único de saúde (art. 200), envolvendo todos os membros do pacto federativo, os quais deverão prever e prover, por meio dos seus respectivos orçamentos, o atendimento às demandas por esse direito.

A realidade brasileira mostra que o acesso à saúde, considerado um direito fundamental e da personalidade, também fica prejudicado pela insuficiência de recursos que garantam o acesso aos serviços médico-hospitalares.

Nessa perspectiva, conforme observa Antonio José Avelãs Nunes e Fernando Facury Scaff, a Constituição definiu as fontes de custeio da saúde, visto que a garantia desse direito 
deve ser financiada por toda a sociedade por meio de um sistema tributário e financeiro capaz de suportar essas despesas. Por isso, o direito à saúde, bem como outros direitos sociais, por demandarem fortes dispêndios e ações por parte do Estado, devem ser analisados em conjunto com as normas do Direito Financeiro, abrangendo três âmbitos de análise: receitas públicas, gastos públicos e crédito público (NUNES; SCAFF, 2011, p. 82-82).

Vale ressaltar, por fim, que a Constituição de 1988 construiu um amplo sistema de proteção social, especialmente no que tange ao direito à saúde. A baixa efetividade do sistema não justifica criticar sua concepção teórica. Em uma afirmativa simples: a concepção foi boa, a efetivação é deficitária. Pode-se concluir, então, que o Brasil está a meio caminho: a concepção de atendimento ao direito à saúde foi alcançada, porém faltam ações políticas que garantam sua efetivação. $\mathrm{O}$ estado da arte, por si só, já explica porque a $8^{\mathrm{a}}$ economia do mundo é, ao mesmo tempo, a 79 ${ }^{\mathrm{a}}$ colocada em indicadores sociais.

\section{CONCLUSÃO}

William Shakespeare foi o mais importante nome da Literatura inglesa de todos os tempos, sendo por muitos considerado um dos mais importantes do mundo. Legou para a Humanidade vasta produção intelectual, comédias, tragédias, poesias e até mesmo peças de natureza histórica.

O Bardo inglês brilhou no período em que se desenvolveu o teatro elisabetano, momento de glória das artes daquele País. A tragédia "A Tempestade" foi sua última obra. Além de conter tramas políticas e amorosas, com traições e conspirações, a peça abordou outro tema igualmente importante: o colonialismo. Por meio de dois personagens, especificamente, o autor coloca frente a frente Próspero, o colonizador, e Caliban, colonizado.

O colonialismo foi um processo contínuo de conquistas de terras, povos e riquezas em lugares distantes dos reinos, especialmente europeus. As ambições políticas de reis eram financiadas por mercadores, também ambiciosos e ávidos por lucro. Pode- 
se afirmar que ele foi uma espécie de embrião do capitalismo. Neste sentido, o capitalismo (em suas fases manufatureira, industrial e financeira, respectivamente) valese do fenômeno da mundialização (globalização) do capital para se expandir por qualquer parte do mundo que lhe despertar algum interesse.

As riquezas geradas pelo capitalismo concentram-se, em grande parte, nas mãos do próprio capitalista. Por um lado, tem-se a multiplicação das riquezas, mas, por outro, a ampliação do processo inexorável de desigualdades econômicas e sociais. A mundialização do capital - o financeiro, em especial - gera, inevitavelmente, a exclusão social.

As desigualdades econômicas e sociais tem se intensificado ao longo do tempo, constituindo-se, no início deste século, em um dos problemas mais graves a serem enfrentados pelos Estados, pelo poder privado e, de modo geral, por todas as pessoas. Mantém-se vivo o desafio de produzir riquezas materiais cuja finalidade seja não apenas medrar as riquezas individuais, mas também atender às necessidades básicas de um contingente cada vez maior de pessoas que ainda não tem acesso ao mínimo vital.

Como resultado, convive-se com a concentração de rendas e capitais e, ao mesmo tempo, com as desigualdades sociais, que atingem a um número cada vez maior de pessoas, em um inexorável processo de violação de direitos da personalidade.

\section{REFERÊNCIAS}

BAUMAN, Zygmunt. A riqueza de poucos beneficia todos nós? Trad. Renato Aguiar. Rio de Janeiro: Zahar, 2015.

BOULOS JÚNIOR, Alfredo. Grandes Autores História. São Paulo: FDT, v. 2, 1995.

CHESNAIS, François. A Mundialização Financeira: gênese, custos e risco. Trad. Carmen Cristina Cacciacarra, Luís Leiria, Silvana Foá e Valéria Coêlho da Paz. São Paulo: Xamã, 1998.

CHESNAIS, François. A Mundialização do Capital. Trad. Silvana Finzi Foá. São Paulo: Xamã, 1996. 
GALVÃO, Tainah Lopes. A Tempestade: o adeus de Shakespeare ao teatro. 24f. 2013. Monografia (Graduação). Dapartamento de Teorias Literárias e Literaturas do Instituto de Letras da UnB. Brasília: UnB, 2013.

HOBSBAWER, Eric J. A Era das Revoluções: Europa 1789-1848. 12. ed. Trad. Maria Tereza Lopes Teixeira e Marcos Penchel. Rio de Janeiro: Paz e Terra, 2000.

INSTITUTO BRASILEIRO DE GEOGRAFIA E ESTATÍSTICA (IBGE). PNAD Contínua 2018: $10 \%$ da população concentram $43,1 \%$ da massa de rendimentos do país. Disponível em: https://agenciadenoticias.ibge.gov.br/agencia-sala-de-imprensa/2013agencia-de-noticias/releases/25700-pnad-continua-2018-10-da-populacao-concentram43-1-da-massa-de-rendimentos-do-pais. Acesso em: 05 abr. 2020.

MINC, Alan. O Triunfo da Mundialização. Trad. Luís Couceito Feto. Lisboa: Instituto Piaget, 1999.

NUNES, António José Avelãs; SCAFF, Fernando Facury. Os Tribunais e o Direito à Saúde. Porto Alegre: Livraria do Advogado, 2011.

ORGANIZAÇÃO DAS NAÇÕES UNIDAS. Banco Mundial: quase metade da população global vive abaixo da linha da pobreza. Disponível em: https://nacoesunidas.org/banco-mundial-quase-metade-da-populacao-global-viveabaixo-da-linha-da-pobreza/. Acesso em: 30 abr. 2020.

ORGANIZAÇÃO DAS NAÇÕES UNIDAS. Relatório de desenvolvimento humano do PNUD destaca altos índices de desigualdade. Disponível em: https://nacoesunidas.org/relatorio-de-desenvolvimento-humano-do-pnud-destaca-altosindices-de-desigualdade-no-brasil/. Acesso em: 28 abr. 2020.

PARADISO, Sílvio Luiz. Literaturas em Língua Inglesa I. Maringá: Unicesumar, 2019.

PUCHNER, Martin. O Mundo da Escrita: como a literatura transformou a civilização. São Paulo: Companhia das Letras, 2019.

SHAKESPEARE, William. A Tempestade. Trad. Ridendo Castigat Mores. S.1., 2000. Disponível em: www.ebooksbrasil.com. Acesso em: 28 abr. 2020.

SHAKESPEARE, William. Otelo. Trad. Beatriz Viégas-Faria. Porto Alegre: L\&PM, 2019a. 
SHAKESPEARE, William. Hamlet. Trad. Pietro Nassetti. São Paulo: Martin Claret, 2001.

SHAKESPEARE, William. Sonhos de uma Noite de Verão. Trad. Beatriz Viégas Faria. Porto Alegre: L\&PM, 2019 b.

SINGER, Paul. O Capitalismo. São Paulo: Moderna, 1998.

SMITH, Adam. A Riqueza das Nações: uma investigação sobre a natureza e as causas da riqueza da nação. Trad. Norberto de Paula Lima. 3. ed. Rio de Janeiro: Nova Fronteira, 2017.

SUTHERLAND, John. Uma Breve História da Literatura. Trad. Rodrigo Breunih. 2. ed. Porto Alegre: L\&PM, 2019.

Data da submissão: $10 / 04 / 2020$

Data da primeira avaliação:23/07/2020

Data da segunda avaliação: 06/08/2020

Data da aprovação: 06/08/2020 